\title{
Article \\ Estimation of Rate Constants and Mixing Characteristics in Flotation Columns
}

\author{
Chul-Hyun Park
}

check for

updates

Citation: Park, C.-H. Estimation of

Rate Constants and Mixing Characteristics in Flotation Columns. Appl. Sci. 2021, 11, 10084. https:// doi.org/10.3390/app112110084

Academic Editors: Nikolaos Koukouzas and Nag-Choul Choi

Received: 17 September 2021

Accepted: 25 October 2021

Published: 28 October 202

Publisher's Note: MDPI stays neutral with regard to jurisdictional claims in published maps and institutional affiliations.

Copyright: (C) 2021 by the author Licensee MDPI, Basel, Switzerland. This article is an open access article distributed under the terms and conditions of the Creative Commons Attribution (CC BY) license (https:// creativecommons.org/licenses/by/ $4.0 /)$
Department of Advanced Energy Engineering, Chosun University, Gwangju 61452, Korea; chpark@chosun.ac.kr; Tel.: +82-062-230-7238

\begin{abstract}
The effect of mixing in a flotation column has long been recognized as an important factor in determining the performance of flotation. The paper presents the effects of mixing on the rate constant in a flotation column, and the establishment of relationships based on vessel dispersion numbers $\left(N_{d}\right)$ that can describe axial dispersion. The rate constants were evaluated using models of plug flow, fully mixed tanks, and axial mixing for a coal cleaning operation. Results showed that fine particles are similar between each model; however, for coarse particles, the deviation is large in the case of perfect mixing, while axial mixing is suitable. It reveals the suitability of using an axial dispersion model for estimating the rate constants, particularly for coarser particles. A regression equation to determine the flotation rate constant was also developed with $N_{d}$ values between 0.2 to 0.5 . The ratio of particles to liquid the residence times time $\left(\tau_{p} / \tau_{L}\right)$ decreases with particle size from small sizes to coarser sizes. Axial dispersion is increased by the superficial gas velocity while is suppressed by the wash water. The relationship between calculated and observed $N_{d}$ can be used with a $94 \%$ accuracy for the coal cleaning application within the range of operating conditions of superficial gas velocity $(0.7-1.6 \mathrm{~cm} / \mathrm{s})$, superficial wash water velocity $(0.1-0.4 \mathrm{~cm} / \mathrm{s})$, and $H_{c} / d_{c}$ (26.8-32.7). The empirical relationship of $N_{d}$ with significant variables along with the aspect ratio of the column was found to be applicable for coal beneficiation. It may be useful in terms of design and scale up of the columns.
\end{abstract}

Keywords: column flotation; axial mixing; collection rate constant; vessel dispersion number

\section{Introduction}

Froth flotation exploits the differences in surface hydrophobicity of the different constituent minerals selectively separates the valuable minerals from gangue by attaching them to air bubbles and recovering them from the mineral laden froth [1-4]. Conventional flotation that uses mechanical cells are widely used in a rougher and more scavenger-like process due to good mixing of pulps but has been known to be ineffective in processing finer mineral particles because of entrainment of fine gangue $[5,6]$. Column flotation has found applicability in the mineral industry owing to its effectiveness in processing fine particles, particularly in cleaning operations where gangue entrainment is reduced [7]. Its effectiveness, simplicity of implementation, and convenience in incorporating automatic control has made it very attractive to be used in processing complex ores which require fine grind sizes $[6,8]$.

The flotation process requires the hydrophobic particles to collide with air bubbles and subsequent bubble-particle attachment to occur for effective separation [9]. In conventional flotation cells, the degree of mixing is relatively high as they process particle sizes that are coarser than those treated in flotation columns. Continuous conventional cells are modelled as fully mixed reactors while batch operations are treated as plug-flow reactors consistent with the residence time of particles being equal $[9,10]$. In columns, however, the degree of mixing varies considerably due to their size, aeration rates, size of rising bubbles, and wash water used to reduce gangue entrainment [11]. Thus, the mixing characteristics have been considered to be between that of fully mixed tanks and plug-flow reactors. 
Hydrodynamics play an important role in the performance of columns since it affects gas dispersion properties, residence time of particles and liquids, as well as mixing and carrying rates $[1,12-15]$. Gas dispersion properties, such as gas superficial velocity $\left(J_{g}\right)$, bubble size $\left(d_{b}\right)$, gas holdup $\left(\varepsilon_{g}\right)$, and bubble surface area flux $\left(S_{b}\right)$ in column flotation, are important parameters which are related to flotation efficiency [16,17]. Especially, bubble size which affects the bubble residence time, the bubble surface area flux, and the carrying rate has long been recognized as an essential factor in evaluating the performance of columns. Many researchers have measured or estimated the bubble size using the relationships between bubble size, its terminal velocity, or its slip velocity within an operating column and gas holdups [2,11,18-21]. Gas holdups depend on numerous factors, such as frother dosage, bubble size, solid percentage, air velocity, particle size, etc. [15,22].

Considerable research efforts have been made to quantify the mixing in columns. Control of mixing is important because the degree of mixing in column flotation may deteriorate flotation efficiency due to selectivity and entrainment [11,23]. The collision/attachment between particles and bubbles resulted from mixing in columns is mainly due to pulp recirculation and the turbulence due to bubble motion in liquid, solid, and gas phases [24,25]. In the case of assuming equal dispersion coefficient for liquids and solids, a decrease in dispersion number results in perfect mixing [23,26]. Meanwhile, Shukla et al. [22] reported that a highly turbulent mixture in the collection zone affects bubble-particle adhesion, which consequently affects the flotation process. Residence time distribution arises from a complex interaction between the profile velocity, diffusion, and turbulence, and it greatly influences the metallurgical performance of flotation [27].

Many studies on the mixing characteristics of industrial columns have been conducted focusing on the perfect mixing model. Massinaei et al. [13] showed that large and small tank-in-series and $\mathrm{N}$ perfect mixers in series were the best models to present the flow pattern of liquid transferred to tailing and concentrate, respectively. Previous researches, using residence time distribution (RTD) data which evaluate the mixing of industrial columns, showed that mixing of cleaner process is similar to fully mixer conditions $[26,28-30]$. Especially, Yianatos's research group has made advances in the design and modeling in the mixing of industrial columns. They reported that the large and small tanks in series (LSTS) as well as the two parallel perfect mixers models were remarkably flexible compared to the other structures, and that the RTD in flotation columns cannot be described by a unique model structure [31,32]. It was also observed that the mixing regime in flotation columns could not be described by a single model structure nor could be related to the cross-sectional shapes or size of columns [31]. Flotation efficiency can be determined by factors, such as size fractions, flows of liquid and solids, and bubble rise velocity, regarding flotation kinetics in continuous operation [33].

Furthermore, dispersion and mixing are the most important characteristics for column geometry $[23,26]$. Several studies have been conducted for the design and scaleup of column flotation by applying the axial dispersion model and the drift flux model $[10,24,25]$. Chegeni et al. [14] reported that values of axial mixing coefficient $(E)$, vessel dispersion number $\left(N_{d}\right)$, bubble diameter $\left(D_{b}\right)$, column height $\left(H_{c}\right)$, and gas holdup $\left(\varepsilon_{g}\right)$ were assumed, and the column diameter was calculated as $5.42(\mathrm{~cm})$.

Considerable research efforts have been mostly made in terms of the large and the industrial columns. In particular, there are few existing researches that applied and compared various models, such as plug flow, fully mixed tanks, and axial mixing in CPT column flotation for coal. This paper discusses the estimation of flotation rate constants based on various models that describe different residence time distributions, including those that describe axial dispersion, in an attempt to identify the most suitable model for column flotation. In addition, we aim to develop an empirical relationship of vessel dispersion number $\left(N_{d}\right)$ that can be applied for designing and scaling up of the flotation columns under operating conditions for coal beneficiation. 


\section{Mixing in Flotation Columns}

In evaluating the performance, it is important to assess the residence time distribution of the particles. Due to the upward flow of air and the downward flow of wash water and feed slurry, some degree of mixing occurs in column in an axial direction. The degree of mixing depends on the flowrates of these streams and the dimensions of the column.

The axial mixing in a column may be described by:

$$
\frac{\partial C}{\partial t}=E\left(\frac{\partial^{2} C}{C \partial^{2}}\right)-u \frac{\partial C}{\partial x},
$$

where $E$ is the axial dispersion coefficient and quantify the degree of mixing and $C$ is the concentration of a given phase (solids or liquid).

As the residence time distribution (RTD) of the given phase is also dependent on the column height $\left(H_{c}\right)$ and its superficial velocity, a vessel dispersion number $\left(N_{d}\right)$ is defined to characterize the mixing process.

$$
N_{d}=\frac{E}{u H_{c}},
$$

It is recognized that the dispersion number for solids differs from that of the liquid and may be defined as:

$$
\begin{gathered}
\text { for liquid } N_{d L}=\frac{E_{L}}{u_{i} H_{c}}, \\
\text { for solid particles } N_{d p}=\frac{E_{p}}{u_{p} H_{c}}
\end{gathered}
$$

The interstitial liquid velocity, $u_{i}$, is given by:

$$
u_{i}=\frac{u_{L}}{1-\varepsilon_{g}},
$$

where $u_{L}$ is the superficial liquid velocity. The particle velocity $u_{p}$ may be calculated in terms of its slip velocity $U_{s p}$ as;

$$
u_{p}=u_{i}+U_{s p},
$$

The slip velocity of particles is estimated by Masliah [21] as:

$$
U_{s p}=\frac{g d_{p}^{2}\left(\rho_{p}-\rho_{s l}\right)\left(1-\varnothing_{s}\right)^{2.7}}{18 \mu_{f}\left(1+0.15 \operatorname{Re}_{p}^{0.687}\right)},
$$

where the particle Reynold's no is given by: $R e_{p}=\frac{d_{p} U_{s p} \rho_{l}\left(1-\varnothing_{s}\right)}{\mu_{f}}$.

Dobby and Finch [26] argued that the axial dispersion coefficient for the liquid and solid phases may be taken as equal and estimated by:

$$
E_{p}=E_{l}=0.063 d_{c}\left(\frac{J_{g}}{1.6}\right)^{0.3} .
$$

Mavros [25] proposed a relationship that is applicable to a wide range of column diameters, albeit, for a limited superficial gas flowrates.

$$
E=\left(9.3 d_{c}-30.1\right) J_{g}^{0.3}
$$

Substituting Equations (5)-(9) in (3),

$$
\text { For liquid : } N_{d L}=\frac{0.063 d_{c}\left(\frac{J_{g}}{1.6}\right)^{0.3}}{\left[\left(J_{s l}\right) /\left(1-\varepsilon_{g}\right)\right] H_{c}}
$$




$$
\begin{gathered}
\qquad N_{d L}=\frac{\left(9.3 d_{c}-30.1\right) J_{g}^{0.3}}{\left[\left(J_{s l} /\left(1-\varepsilon_{g}\right)\right)\right] H_{c}} \\
\text { For particles : } N_{d p}=\frac{0.063 d_{c}\left(\frac{J_{g}}{1.6}\right)^{0.3}}{\left[\left(J_{s l}\right) /\left(1-\varepsilon_{g}\right)+U_{s p}\right] H_{c}}
\end{gathered}
$$

Dobby and Finch [26],

$$
N_{d p}=\frac{\left(9.3 d_{c}-30.1\right) J_{g}^{0.3}}{\left[\left(J_{s l} /\left(1-\varepsilon_{g}\right)\right)+U_{s p}\right] H_{c}},
$$

Mavros [25],

Note: $J_{s l}$ includes the superficial rate of wash water and that of feed water.

These relationships are used with the data from the coal processing application reported in this work to evaluate the extent of mixing in the column.

\section{Flotation Recovery Models}

Flotation performance has generally been modelled based on first kinetics with suitable modifications to account for unfloatable minerals, for example [21]. In conventional batch cells, all particles spend the same length of time and, hence, their performance may be modelled similar to plug-flow reactors.

Plug flow model: for a first-order rate reaction with a rate constant $k_{c}$, exhibiting plug flow transport and a retention time $t$, recovery $R_{c}$ is given by

$$
R_{c}=1-\exp \left(-k_{c} t_{p}\right),
$$

where $t_{p}$ is the mean residence time of particles.

Perfect mixing model: Continuously operated flotation cells are considered to behave like fully mixed reactors, and the residence time distribution (RTD) of particles is shown to approximate a negative exponential distribution. For a system exhibiting such perfect mixing behaviour with a mean residence time $\tau$ :

$$
R_{c}=1-\left(1+k_{c} \tau_{p}\right)^{-1},
$$

The performance of counter-current flotation columns are considered to be in between those of plug flow and fully mixed reactors due to the axial mixing that occurs within the column, as described earlier. Axial mixing and, in turn, the RTD of the particles is affected by the superficial velocity of the slurry, gas holdup in the column, slip velocity of the particles, and the column height.

For a counter-current column operation, the particle residence time $\tau_{p}$ can be estimated by $\mathrm{Xu}$ and Finch [10]:

$$
\tau_{p}=\tau_{L}\left(\frac{J_{s l} /\left(1-\varepsilon_{g}\right)}{J_{s l} /\left(1-\varepsilon_{g}\right)+U_{s p}}\right),
$$

and the liquid residence time $\tau_{L}$ is given as:

$$
\tau_{L}=\frac{H_{c}\left(1-\varepsilon_{g}\right)}{J_{s l}},
$$

The recovery of solids in such a column with axial mixing as characterized by the vessel dispersion number, $N_{d}$, can be given by Levenspiel [34]:

$$
R_{c}=1-\frac{4 a \exp \left(\frac{1}{2 N_{d}}\right)}{(1+a)^{2} \exp \left(\frac{a}{2 N_{d}}\right)-(1-a)^{2} \exp \left(\frac{-a}{2 N_{d}}\right)}
$$


where

$$
a=\left(1+4 k_{c} \tau_{p} N_{d}\right)^{1 / 2}
$$

In the extreme case of axial mixing approaching plug flow, $N_{d} \rightarrow \infty$, Equation (18) reduces to Equation (15), representing perfect mixing operation. Similarly, in the absence of axial mixing, $N_{d} \rightarrow 0$, i.e., negligible dispersion, leads to Equation (14) which is applicable for plug flow transport.

\section{Experimental}

\subsection{Materials}

Coal sample (anthracite) used in this study was obtained from Hwa-Sun Coal Mine in South Korea. It is a low rank coal which was rejected as waste from the main processing plant. On analysis, it was revealed that the ash in this coal could be liberated at about $150 \mu \mathrm{m}$ in size. Thus, the raw coal was grinded to this size to be used as feed material for the testwork in a laboratory CPT CoalPro column flotation system.

\subsection{Equipment and Procedures}

A schematic diagram of the flotation column and the superficial flowrates of each stream are shown in Figure 1 in which $F, C$, and $T$ refer to the feed, concentrate, and tailings streams, and subscripts $w$, $s$, and $g$ refer to flowrates of water, solids, and gaseous components. $J$ is the superficial velocity (i.e., volumetric flowrate area of the cross-section of the column). Features of the laboratory CPT CoalPro column flotation system used are: (1) the height and diameter of column at $1500 \mathrm{~mm}$ and $55 \mathrm{~mm}$, respectively; (2) Sparger, a porous HDPE or optional cavitation tube; and (3) automatic control for level, sparger air, and wash water. The column upper section consists of wash water distributor, froth collection launder, and feeder while the lower section houses the sparger (bubble generator) and tailings outlet. The feed slurry inlet is at a point of $1 / 3$ of the column height from the top. The wash water was fed at the top of the column while the tailings were collected at the bottom of the column. The concentrate and tailings products were collected and dried in the dryer of $105^{\circ} \mathrm{C}$ for $24 \mathrm{~h}$.

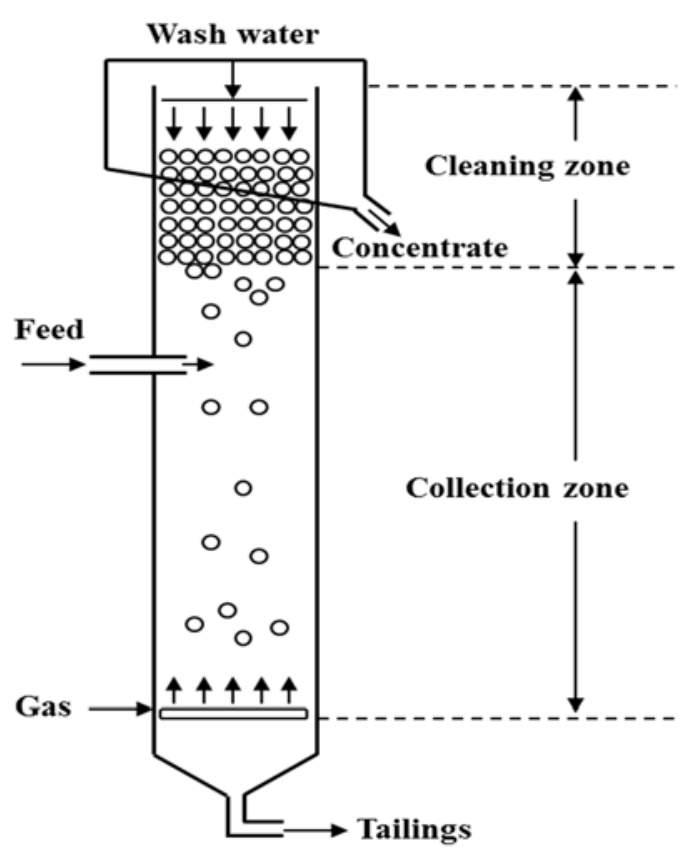

(a)

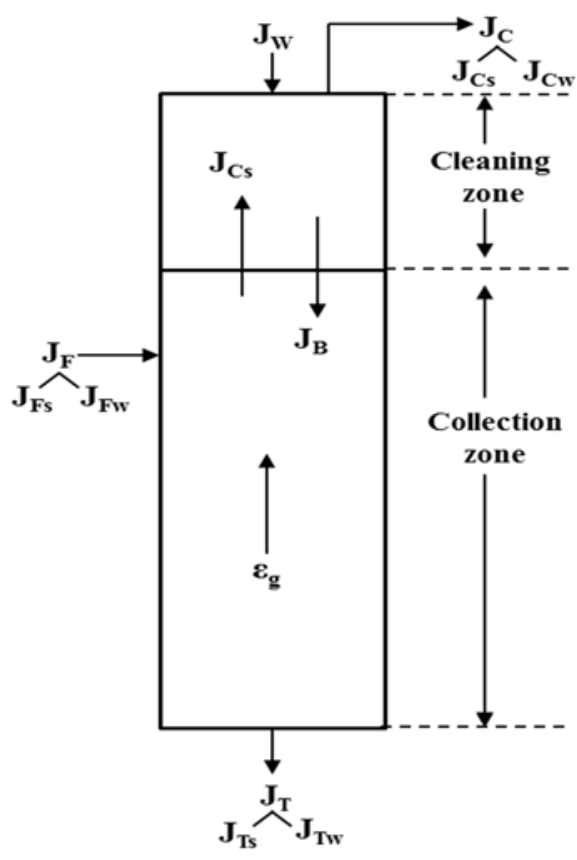

(b)

Figure 1. (a) Schematic diagram of flotation column and (b) superficial velocities in column. 
The reagents tested were collectors (kerosene and a patented collector developed for coal, DMU-101), frothers (MIBC), and depressants (sodium metaphosphate (SMP)). The conditions of variables tested in flotation column were as follows: superficial gas velocity of $0.7-1.6 \mathrm{~cm} / \mathrm{s}$, superficial wash water velocity of $0.1-0.4 \mathrm{~cm} / \mathrm{s}$, feed solids concentration of $1-10 \%$ by mass, DMU-101 of $0.2-0.6 \mathrm{~kg} / \mathrm{t}$, and SMP of $1.5-4.5 \mathrm{~kg} / \mathrm{t}$.

Prior to conducting flotation tests using coal, gas holdup measurements were carried out under various air and wash water flowrates and frother combinations by measuring the difference in interface level as a result of stopping the air supply. The contents of ash, fixed carbon, volatile materials, and moisture were measured using proximate analyzer (TGA601, LECO Ltd., St. Joseph, MI, USA). A field emission-scanning electron microscope (FE-SEM, S-4800, Hitachi, Tokyo, Japan) equipped with an energy dispersive X-ray spectrometer (EDS, Link Isis 3.0, Oxford Instrument plc, Abingdon, Oxfordshire, UK) was used for this analysis of coal samples. A platinum coating was applied to each coal product sample using a Pt electron E-1030 sputter according to the standard procedure which yielded a platinum layer of 6-7 microns.

\section{Result and Discussion}

A size analysis of coal particles transferred from the feed to the concentrate product was conducted. From the size distributions and the mass flow rate of the concentrate and feed measured, a performance curve for the column was constructed. Figure 2 shows a plot of the fraction of solids recovered in the concentrate $(C / F)$ versus particle size. The trend is as expected in flotation cells, in that the recovery is maximal in the range $30-100 \mu \mathrm{m}$ and decreases for fine and larger particles. Typically, flotation performance is highest in the region of intermediate particle size and decreases at the finer and larger sizes. There are lots of effects, such as mineral liberation, floatable mineral, reagents, flotation time etc. However, in terms of particle-bubble interaction, finer particles may be the low collision and attachment efficiency to bubble, which have insufficient inertia to cross the water streamlines around the coursing bubble [35]. In case of coarse particles, this is due to the high detachment probability to bubble including decreased mineral liberation $[35,36]$.

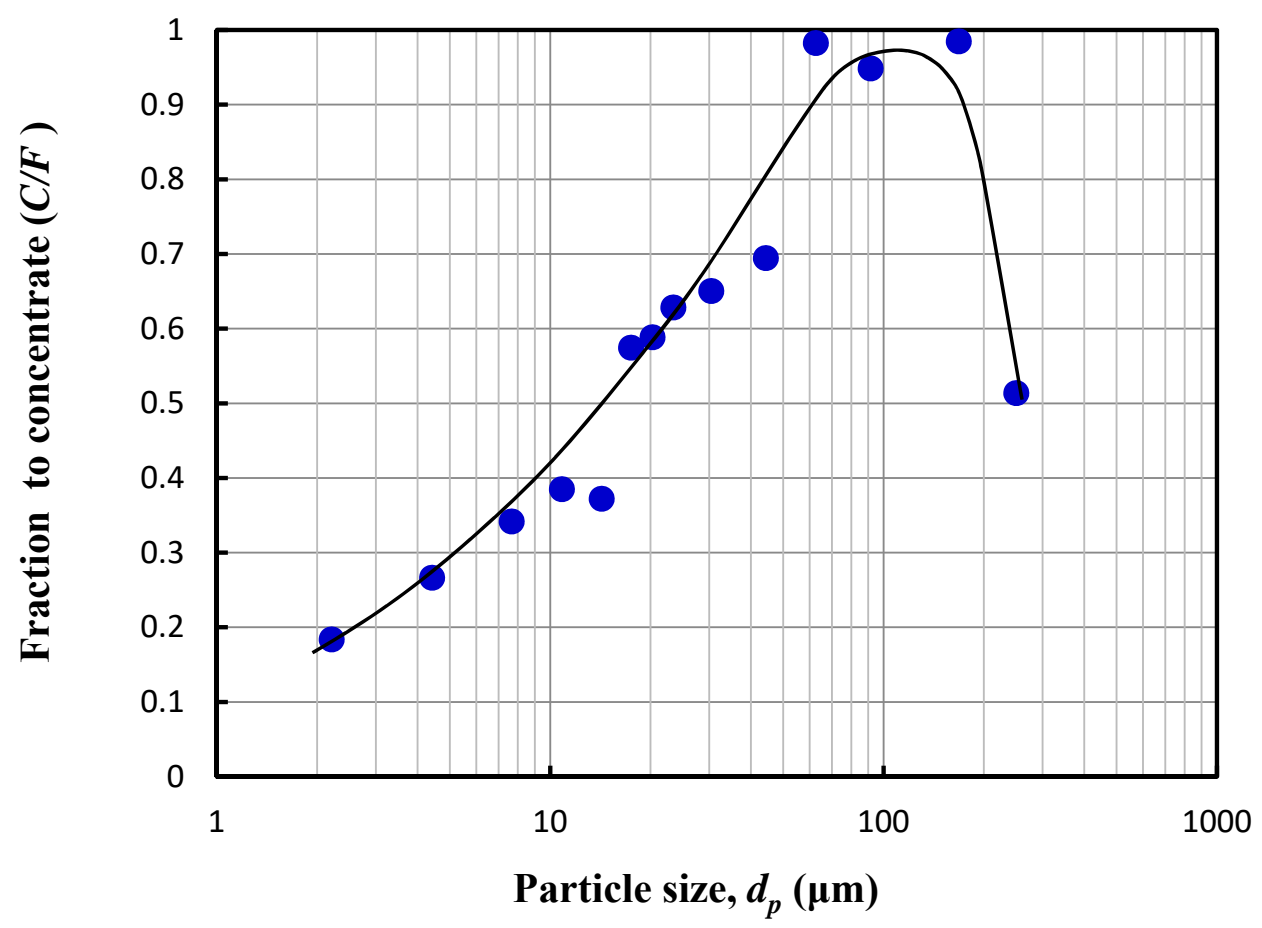

Figure 2. Performance curve as fraction to concentrate $(C / F)$ vs. particle size $\left(d_{p}\right)$. 
Based on the performance curve in Figure 2, the mean particle residence times of particles were calculated using Equation (16) and used in Equations (14), (15) and (18) to estimate the flotation rate constants that correspond to plug flow, fully mixed, and axial mixing conditions. Figure 3 shows the variation of these rate constants against particle size. It shows that the flotation rate constants are similar below about $40 \mu \mathrm{m}$. It is, as expected, as the residence time of finer particles equals that of the water. Furthermore, it has been also reported that, for finer particles, solid axial mixing is the same as fluid axial mixing [11]. For intermediate particle sizes, the estimated rate constants vary considerably but those evaluated using plug flow and axial dispersion are closer to each other than those due to a perfect mixing model. In particular, in the case of coarse particles, the deviation is large in the case of perfect mixing, while axial mixing is suitable. Thus, it has been shown that the mixing characteristics of a flotation column affect the flotation rate constant, particularly for coarser particles. Thus, it shows that the axial mixing is prevalent in columns under the operating conditions tested and the perfect mixing model is not suitable for modelling small column performance. Normally, the mixing characteristics in column are considered to be between that of plug-flow reactors and fully mixed tanks. In addition, the axial-dispersed model can describe the hydrodynamics of laboratory or pilot scale columns properly, but due to the limitations it cannot be used for industrial columns [8].

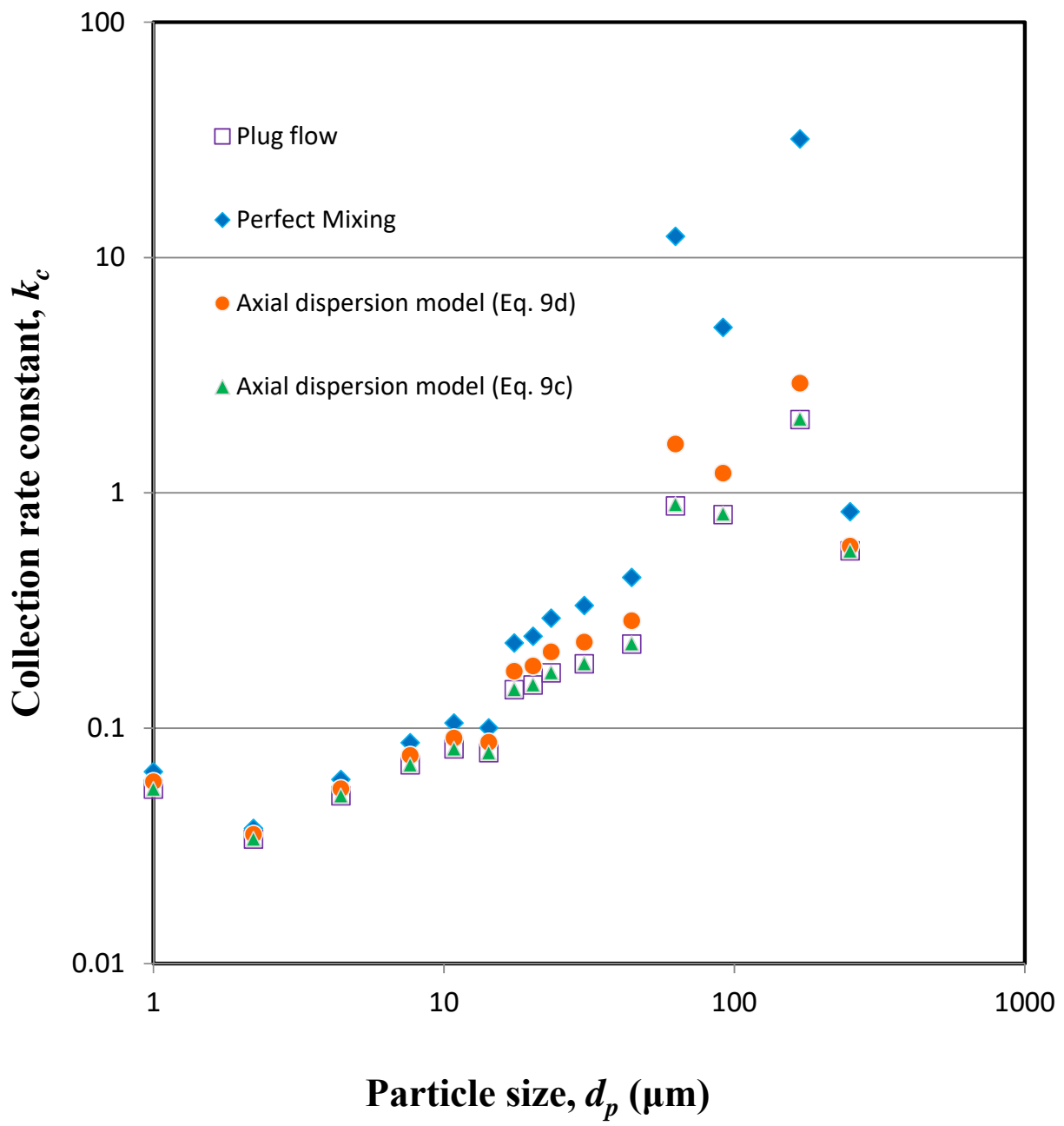

Figure 3. Comparison of calculated collection rate constant $\left(k_{c}\right)$ vs. particle size $\left(d_{p}\right)$ under various flow conditions of particles in the column.

A consequence of mixing is its effect on the residence time distribution of particles and the liquid. Figure 4 shows the ratio of the residence times of particles and liquid against 
particle size. As can be seen, this ratio decreases with particle size from unity at small sizes to lower values at coarser sizes. The points corresponding to this study agrees well with Yianatos and Bergh [37] but deviates from those of Dobby and Finch [26], particularly for finer particles. It may be due to their assumption that the axial dispersion coefficient is equal for both liquid and particles. It also illustrates the effect of solids density as Dobby and Finch data were obtained for particle density of 5.19 and the coal used in this study has a density of 1.86. The data of Yianatos and Bergh had a density of 3.6 and are close to those of this study. As can be seen from the figure, the effect of solids density is to decrease the ratio $\left(\tau_{p} / \tau_{L}\right)$, particularly for finer particle sizes. The fact that the particle residence time varies with the degree of mixing is important in determining the performance of flotation columns.

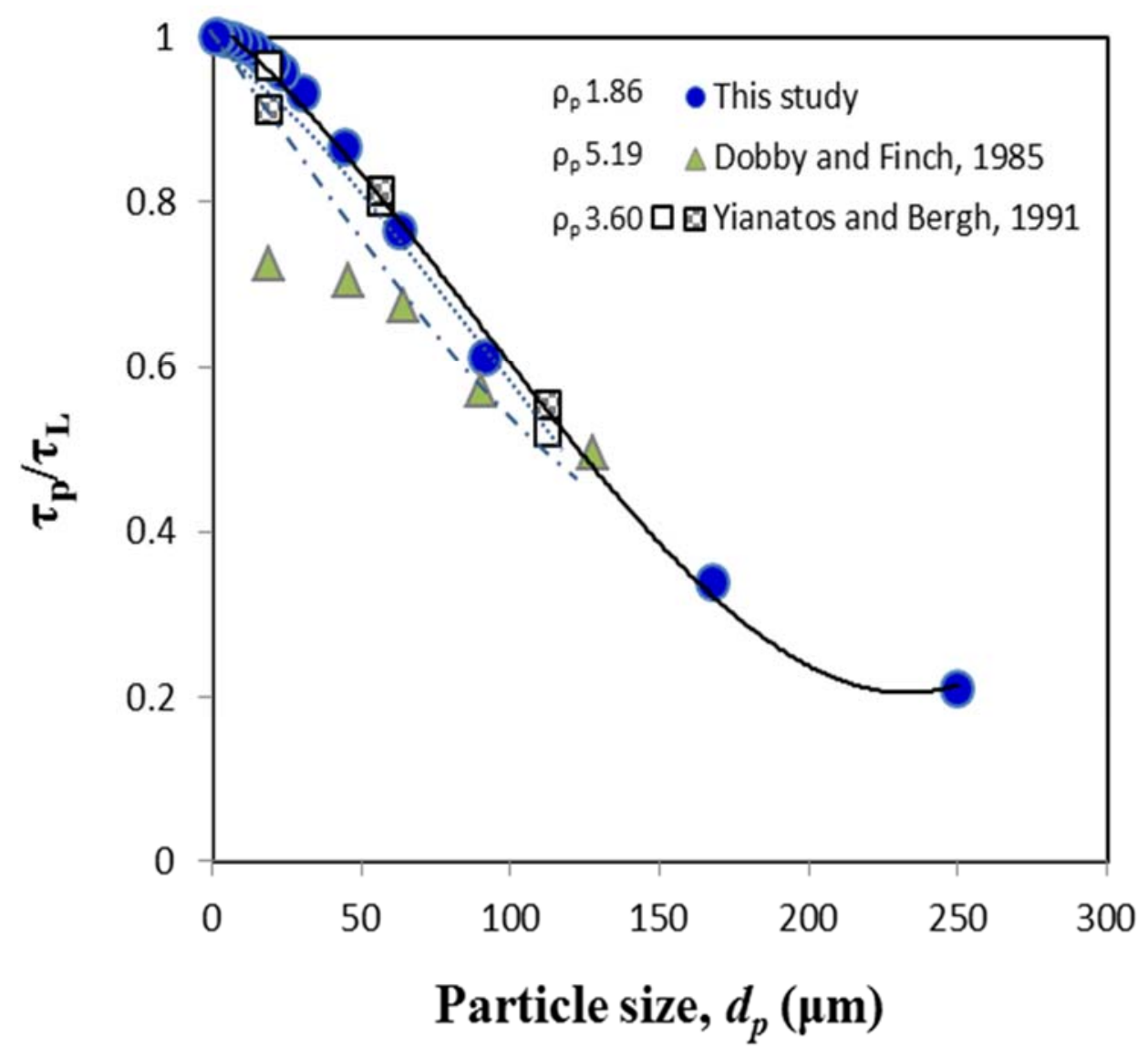

Figure 4. Ratio of particle mean residence time to liquid mean residence time $\left(\tau_{p} / \tau_{L}\right)$ versus particle size.

Intensity of axial mixing is related to vessel dispersion number, residence time distribution, superficial gas velocity, and the column diameter, etc. [23]. The effect of vessel dispersion number, $N_{d}$, which is a measure of the degree of mixing and the particle residence time $\left(\tau_{p}\right)$, are affected by both superficial flowrate of gas and slurry/water as shown in the Figure 5. As can be seen, it increases with $J_{g}$ and decreases with $J_{s l}$. An increase in the vessel dispersion number with an increase in the superficial gas velocity is because of the increase in the gas holdup. The increased gas holdup results in the phenomenon of cloud bubbles generated from an increase in the aeration rate, and it then increases the axial mixing due to the turbulence [10,38]. The superficial slurry velocity deceases the gas holdup, and then liquid/slurry volume of downstream leads to a reduction in the axial mixing. 


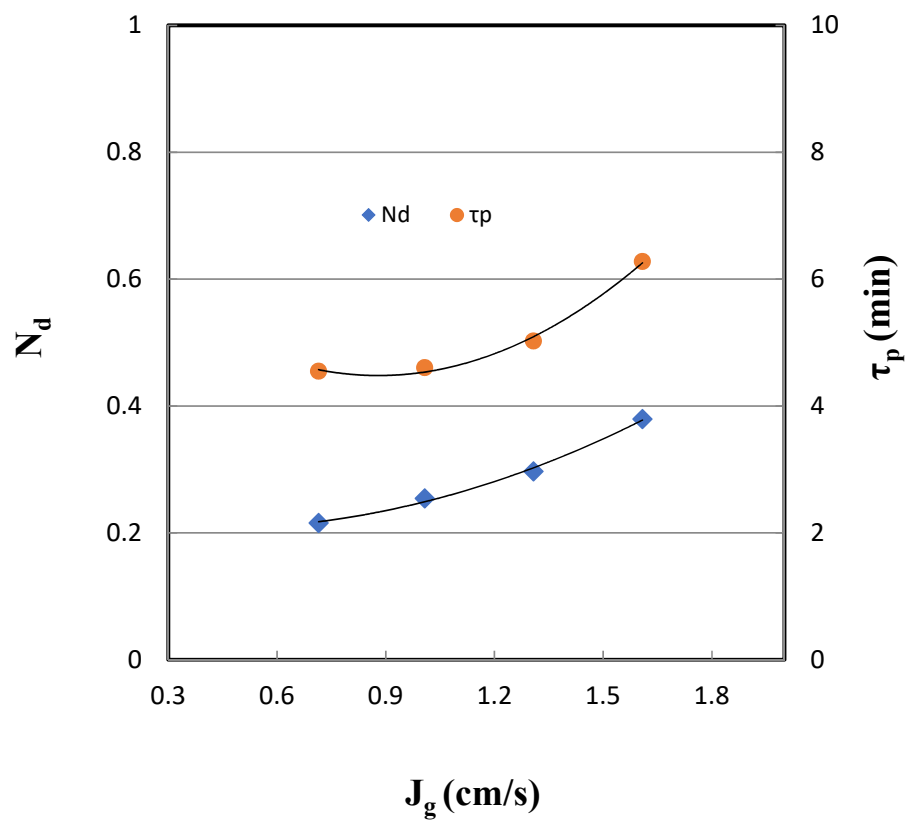

(a)

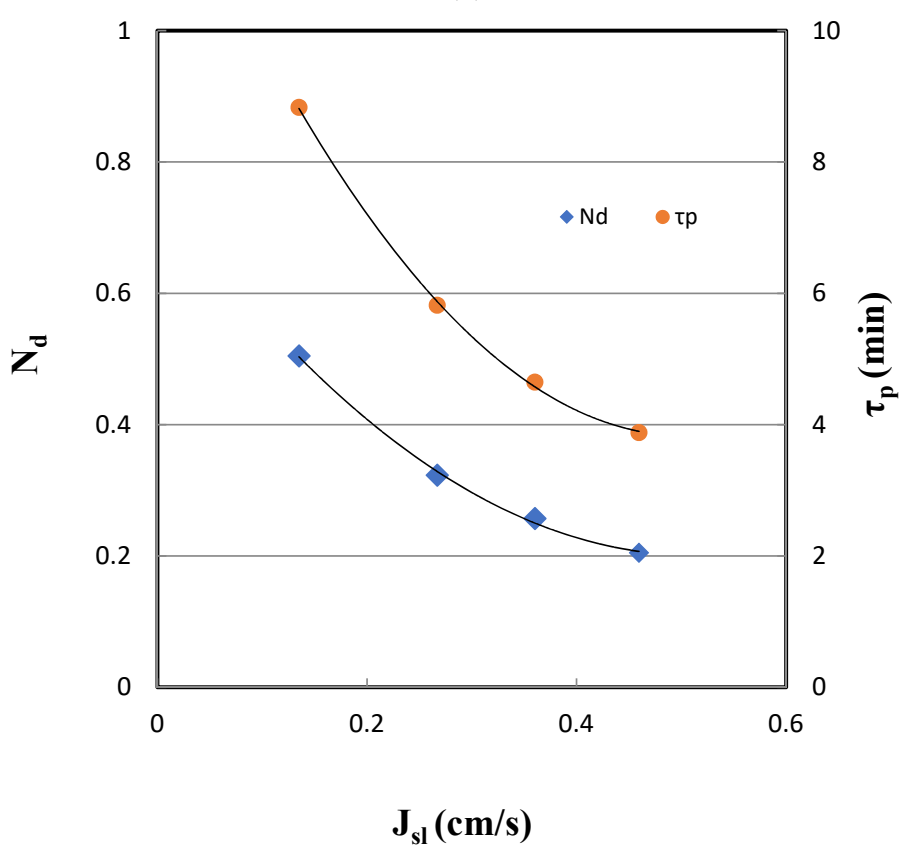

(b)

Figure 5. Effect of (a) superficial gas flowrate and (b) superficial slurry flowrate on vessel dispersion number.

Dispersion and mixing are the most important characteristics in terms of design and scale up of the flotation columns. It may be useful to establish the variation of $N_{d}$ with the above significant variables along with the aspect ratio of the column given by $\left(H_{c} / d_{c}\right)$, to estimate the extent of mixing.

For the coal cleaning operation described here, it may be given by a regression relationship of the form:

$$
N_{d}=0.079 U_{s}^{0.288}\left(\frac{J_{g}}{J_{s l}}\right)^{0.615}\left(\frac{H_{c}}{d_{c}}\right)^{-0.019},
$$


where $H_{c}$ is the height of the collection zone and $d_{c}$ the diameter of the column. The variation in $H_{c}$ arise due to variations in gas holdup in the column.

Relationship between calculated and observed vessel dispersion number $\left(N_{d}\right)$ are shown in Figure 6. The relationship can be used with $94 \%$ accuracy for the coal cleaning application within the range of operating variables tested in superficial gas velocity $(0.7-1.6 \mathrm{~cm} / \mathrm{s})$, superficial wash water velocity $(0.1-0.4 \mathrm{~cm} / \mathrm{s})$, and $H_{c} / d_{c}(26.8-32.7)$. As shown in Figure 7, a regression equation may also be developed to determine the variation of the flotation rate constant with vessel dispersion number to estimate the former in terms of the operating variables. Flotation efficiency of coal can be predicted by adjusting the dispersion number according to the conditions of the above mixing characteristic variables.

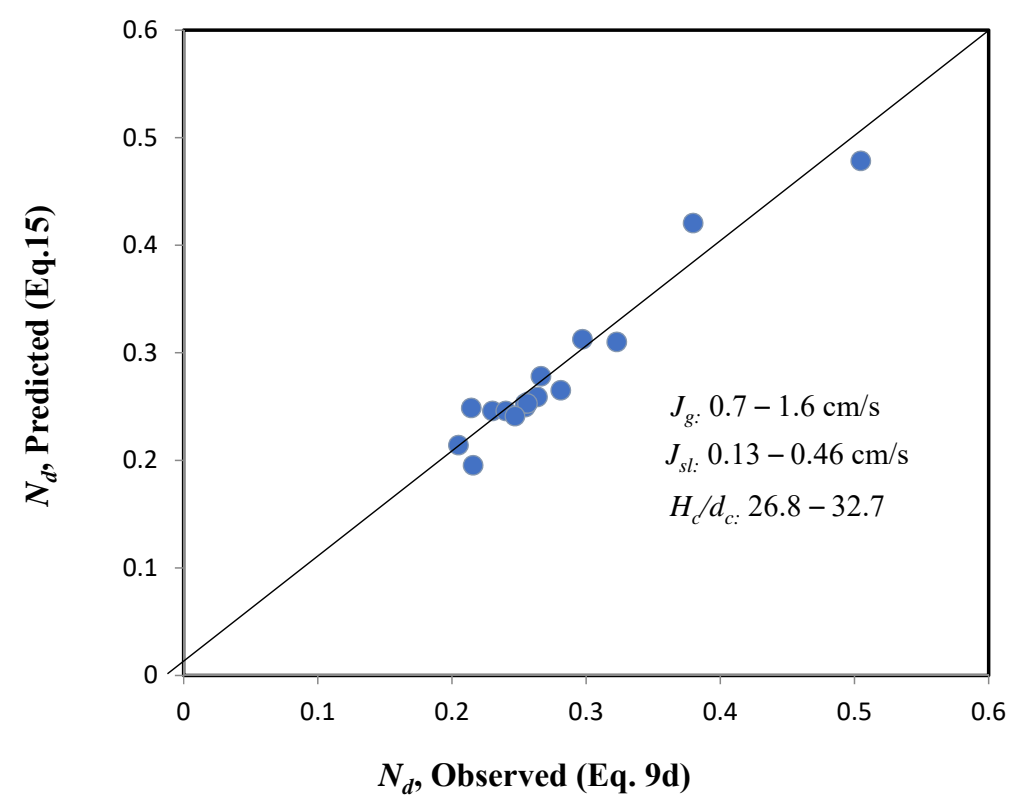

Figure 6. Relationship between calculated and observed vessel dispersion number, $N_{d}$.

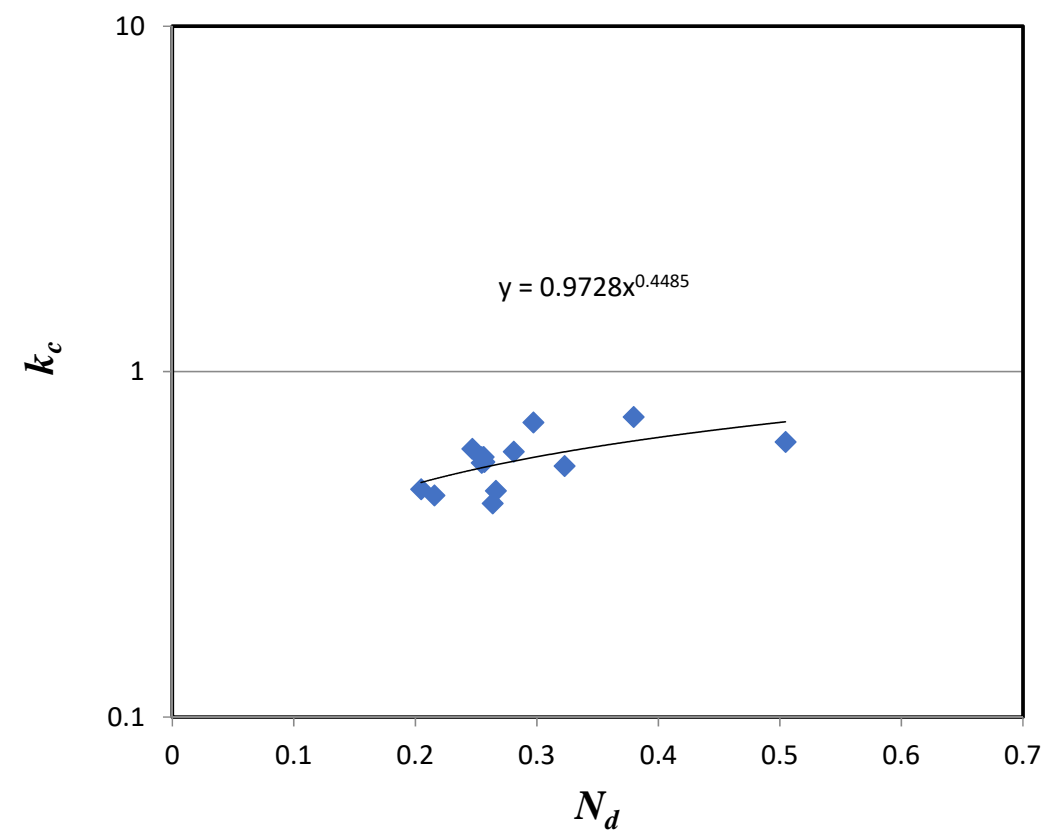

Figure 7. Plot of collection rate constant $\left(k_{c}\right)$ versus vessel dispersion number $\left(N_{d}\right)$. 


\section{Conclusions}

The effect of mixing in a flotation column on the flotation rate constant and various relationship in relation to residence time distributions was estimated and developed. A performance curve $(C / F)$ for the column showed that the recovery is maximal in the range 30-100 $\mu \mathrm{m}$ and decreases for fine and larger particles. In terms of particle-bubble interaction, finer and coarser particles occur due to the low collision and the high detachment probability to bubble, respectively. The flotation rate constants were estimated by mixing models against the particle size. It showed that fine particles are similar between each model but, for coarse particles, the deviation is large in the case of perfect mixing, while axial mixing is suitable. It reveals that the mixing characteristics of a flotation column affect the flotation rate constant, particularly for coarser particles.

The ratio of particles to liquid as well as the residence times $\left(\tau_{p} / \tau_{L}\right)$ decrease with the particle size, from small sizes to coarser sizes. The effect of solids density is to decrease the ratio $\left(\tau_{p} / \tau_{L}\right)$ particularly for finer particle sizes. Axial dispersion is increased by the superficial gas velocity while it is suppressed by the wash water. It therefore seems that gas holdup, which has cloud bubbles by aeration, increases, which then increases the axial mixing due to the turbulence, whereas liquid volume of downstream leads to a reduction in mixing.

Regression relationships have also been established to estimate the rate constants and prevailing vessel dispersion numbers $\left(N_{d}\right)$. Relationship between calculated and observed $N_{d}$ can be used with $94 \%$ accuracy for the coal cleaning application within the range of operating variables tested in superficial gas velocity of $0.7-1.6 \mathrm{~cm} / \mathrm{s}$, superficial wash water velocity of $0.1-0.4 \mathrm{~cm} / \mathrm{s}$, and $H_{c} / d_{c}$ of 26.8-32.7. A regression equation to determine the flotation rate constant was also developed with $N_{d}$ values between 0.2 to 0.5 . In terms of design and scale up of the flotation columns, an empirical relationship of $N_{d}$ along with the aspect ratio of the column was found to be applicable for coal beneficiation.

A regression relationship can be given by:

$$
N_{d}=0.079 U_{s}^{0.288}\left(\frac{J_{g}}{J_{s l}}\right)^{0.615}\left(\frac{H_{c}}{d_{c}}\right)^{-0.019} .
$$

Funding: This study was supported by research fund from Chosun University, 2017.

Institutional Review Board Statement: Not applicable.

Informed Consent Statement: Not applicable.

Data Availability Statement: Data are available on request to the authors.

Acknowledgments: I would deeply appreciate to Nimal Subasinghe for a lot of instruction and inspiration. He has made great contributions and outstanding achievements in education and research in the field of mineral processing for a long time, and retired in the end of 2018 at Department of Metallurgical \& Minerals Engineering, WA School of Mines, Curtin University, Australia. I hope his future is full of happiness and good things.

Conflicts of Interest: The authors declare no conflict of interest.

\section{References}

1. Deglon, D.; Egya-Mensah, D.; Franzidis, J. Review of hydrodynamics and gas dispersion in flotation cells on South African platinum concentrators. Miner. Eng. 2000, 13, 235-244. [CrossRef]

2. Zednikova, M.; Crha, J.; Vobecká, L.; Basařová, P.; Vejrazka, J.; Tihon, J. Collision of Bubbles with Solid Surface in the Presence of Specific Surfactants. Minerals 2021, 11, 442. [CrossRef]

3. Corpas-Martínez, J.R.; Pérez, A.; Amor-Castillo, C.; Navarro-Domínguez, R.; Martín-Lara, M.A.; Calero, M. Optimal Depressants and Collector Dosage in Fluorite Flotation Process Based on DoE Methodology. Appl. Sci. 2019, 9, 366. [CrossRef]

4. Altun, N.E.; Hicyilmaz, C.; Hwang, J.Y.; Bagci, A.S. Beneficiation of Himmetoğlu oil shale by flotation as a solid fuel substitute. Part 1. Materials characteristics and flotation behavior. Energy Fuels 2006, 20, 214-221. [CrossRef]

5. Vera, M.; Franzidis, J.; Manlapig, E. Simultaneous determination of collection zone rate constant and froth zone recovery in a mechanical flotation environment. Miner. Eng. 1999, 12, 1163-1176. [CrossRef] 
6. Sastri, S.R.S.; Reddy, P.S.R.; Bhattacharyya, K.; Kumar, S.G.; Narasimhan, K.S. Recovery of coal fines using column flotation. Miner. Eng. 1988, 1, 359-363. [CrossRef]

7. Mills, P.J.T.; O'Connor, C.T. The modelling of liquid and solids mixing in a flotation column. Miner. Eng. 1990, 3, 567-576. [CrossRef]

8. Gomaa, H.G.; Al Taweel, A.M. Axial mixing in a novel pilot scale gas-liquid reciprocating plate column. Chem. Eng. Process. 2005, 44, 1285-1295. [CrossRef]

9. Finch, J.A.; Dobby, G.S. Column flotation: A selected review. Part I Int. J. Miner. Process. 1991, 33, 343-354. [CrossRef]

10. Xu, M.; Finch, J.A. Solids mixing in the collection zone of flotation columns. Miner. Eng. 1992, 5, 1029-1039. [CrossRef]

11. Finch, J.A.; Dobby, G.S. Column Flotation; Pergamon Press: Sydney, Australia, 1991; p. 180.

12. Zhou, Y.; Albijanic, B.; Tadesse, B.; Wang, Y.; Yang, J. Investigation of bubble-particle attachment interaction during flotation. Miner. Eng. 2019, 13, 91-94. [CrossRef]

13. Massinaei, M.; Kolahdoozan, M.; Noaparast, M.; Oliazadeh, M.; Sahafipour, M.; Finch, J.A. Mixing characteristics of industrial columns in rougher circuit. Miner. Eng. 2007, 20, 1360-1367. [CrossRef]

14. Chegeni, M.H.; Abdollahy, M.; Khalesi, M.R. Column flotation cell design by drift flux and axial dispersion models. Int. J. Miner. Process. 2015, 145, 83-86. [CrossRef]

15. Bhunia, K.; Kundu, G.; Mukherjee, D. Statistical model for gas holdup in flotation column in presence of minerals. Can. Metall. $Q$. 2015, 54, 235-246. [CrossRef]

16. Hernandez, H.; Gomez, C.O.; Finch, J.A. Gas dispersion and de-inking in a flotation column. Miner. Eng. 2003, 16, 739-744. [CrossRef]

17. Han, Y.; Zhu, J.; Shen, L.; Zhou, W.; Ling, Y.; Yang, X.; Wang, S.; Dong, Q. Bubble Size Distribution Characteristics of a Jet-Stirring Coupling Flotation Device. Minerals 2019, 9, 369. [CrossRef]

18. Vandenberghe, J.; Choung, J.; Xu, Z.; Masliyah, J. Drift Flux Modelling for a Two-Phase System in a Flotation Column. Can. J. Chem. Eng. 2005, 83, 169-176. [CrossRef]

19. Fu, Y.; Liu, Y. Experimental study of bubbly flow using image processing techniques. Nucl. Eng. Des. 2016, 310, 570-579. [CrossRef]

20. Mills, P.J.T.; O'Connor, C.T. Technical note the use of the axial dispersion model to describe mixing in a flotation column. Miner. Eng. 1992, 5, 939-944. [CrossRef]

21. Masliyah, J.H. Hindered settling in a multi-species particle system. Chem. Eng. Sci. 1979, 34, 1166-1168. [CrossRef]

22. Shukla, S.C.; Kundu, G.; Mukherjee, D. Study of gas holdup and pressure characteristics in a column flotation cell using coal. Miner. Eng. 2010, 23, 636-642. [CrossRef]

23. Mankosa, M.J.; Luttrell, G.H.; Adel, G.T.; Yoon, R.H. A study of axial mixing in column flotation. Int. J. Miner. Process. 1992, 35, 51-64. [CrossRef]

24. Yianatos, J.B.; Bergh, L.G.; Díaz, F.; Rodríguez, J. Collection zone kinetic model for industrial flotation columns. Miner. Eng. 2005, 18, 1373-1377. [CrossRef]

25. Mavros, P. Mixing in flotation columns. Part I: Axial dispersion modelling. Miner. Eng. 1993, 6, 465-478. [CrossRef]

26. Dobby, G.S.; Finch, J.A. Mixing characteristics of industrial flotation columns. Chem. Eng. Sci. 1985, 40, 1061-1068. [CrossRef]

27. Yianatos, J.B.; Bergh, L.G.; Vinnett, L.; Panire, I.; Díaz, F. Modelling of residence time distribution of liquid and solid in mechanical flotation cells. Miner. Eng. 2015, 78, 69-73. [CrossRef]

28. Lelinski, D.; Allen, J.; Redden, L.; Weber, A. Analysis of the residence time distribution in large flotation machines. Miner. Eng. 2002, 15, 499-505. [CrossRef]

29. Espinosa-Gomez, R.; Johnson, N.; Pease, J.; Munro, P. The commissioning of the first flotation columns at Mount Isa Mines Limited. In Processing of Complex Ores; Elsevier: Amsterdam, The Netherlands, 1989; pp. 293-302.

30. Yianatos, J.B.; Bergh, L.G.; Díaz, F.; Rodríguez, J. Mixing characteristics of industrial flotation equipment. Chem. Eng. Sci. 2005, 60, 2273-2282. [CrossRef]

31. Yianatos, J.B.; Bergh, L.G.; Vinnett, L.; Rojas, I. On the collection of valuable minerals along rougher flotation banks. Miner. Eng. 2014, 66, 202-206. [CrossRef]

32. Yianatos, J.B.; Vinnett, L.G.; Panire, I.; Alvarez-Silva, M.; Díaz, F. Residence time distribution measurements and modelling in industrial flotation columns. Miner. Eng. 2017, 110, 139-144. [CrossRef]

33. Yianatos, J.B.; Bergh, L.G.; Vinnett, L.; Contreras, F.; Díaz, F. Flotation rate distribution in the collection zone of industrial cells. Miner. Eng. 2010, 23, 1030-1035. [CrossRef]

34. Levenspiel, O. Chemical Reaction Engineering; John Wiley \& Sons: Hoboken, NJ, USA, 1988.

35. Wills, B.A.; Finch, J.A. Wills' Mineral Processing Technology: An Introduction to the Practical Aspects of Ore Treatment and Mineral Recovery; Butterworth-Heinemann: Oxford, UK, 2015.

36. You, X.; Li, L.; Liu, J.; Wu, L.; He, M.; Lyu, X. Investigation of particle collection and flotation kinetics within the Jameson cell downcomer. Powder Technol. 2017, 31, 221-227. [CrossRef]

37. Yianatos, J.B.; Bergh, L.G. RTD studies in an industrial flotation column: Use of the radioactive tracer technique. Int. J. Miner. Process. 1992, 36, 81-91. [CrossRef]

38. Rao, N.V.R.; Baird, M.H. Axial mixing and gas holdup with reciprocating doughnut plates. Can. J. Chem. Eng. 2000, 78, 261-264. [CrossRef] 